\title{
Google Cloud Platform Adoption for Teaching in HEIs: A Qualitative Approach
}

\section{Popoola Kareem Hamed*, Abdul Shakour Preece}

Faculty of Education, International Islamic University Malaysia, Kuala Lumpur, Malaysia

Email: *popoolaamir@gmail.com

How to cite this paper: Hamed, P.K. and Preece, A.S. (2020) Google Cloud Platform Adoption for Teaching in HEIs: A Qualitative Approach. Open Access Library Journal, 7: e6819.

https://doi.org/10.4236/oalib.1106819

Received: September 14, 2020

Accepted: November 15, 2020

Published: November 18, 2020

Copyright $\odot 2020$ by author(s) and Open Access Library Inc.

This work is licensed under the Creative Commons Attribution International License (CC BY 4.0).

http://creativecommons.org/licenses/by/4.0/

(c) (i) Open Access

\begin{abstract}
Higher educational institutions (HEIs) are continuing to struggle with mounting fiscal problems due to economic downturn, which are increasingly forcing information technology (IT) departments to do more with same or less budgets. One area of growing interest for meeting the high technology demands and minimizing costs is the use of Google Cloud Platform to centralize computing and information management functions. Google Cloud Platform is a rapidly growing, yet evolving model that offers significant advantages to these institutions and is being widely used by large \& small corporate organizations to manage their IT provisions and reduce their operational as well as IT maintenance costs. The use of Google Cloud Platform could also possibly allow HEIs to shift resources normally allocated for procurement, infrastructure, development, maintenance, and staffing to pay-as-you-go services to minimize operational \& maintenance costs. However, despite such potential benefits of Google Cloud Platform higher educational institutions are yet to reap the benefits of this emerging technology as can be witnessed by snail pace adoption of Google Cloud Platform solutions. This paper thus intends to investigate the factors which could affect the acceptance and use of Google Cloud Platform in HEIs especially in developing economies like Malaysia.
\end{abstract}

\section{Subject Areas}

Education

\section{Keywords}

Google Cloud Platform Adoption; Economies Development, Higher

Education Institution

\section{Introduction}

Higher education institutions (HEIs) don't seem to be immune to recent eco- 
nomic downturn effects. HEIs have witnessed their endowments disappear and their operating budgets severely shrinking. These financial constraints are making it extremely difficult for HEIs to operate effectively and efficiently. Businesses, government or universities, etc. require large investments, financially and human resource wise, for purchase and maintenance of computing assets. (Ayyad, 2015) [1]. This is posing a lot of difficulties for HEIs to provide necessary IT support for running their operational activities such as administrative, teaching and research activities (Sife, Lwoga, \& Sanga, 2007) [2], thus, increasing the need for efficient and economical methods to provide information technology services (Dominguez, 2013) [3]. Google Cloud Platform offers a solution to these problems by helping to reduce technology costs and manpower requirements. Google Cloud Platform is an information technology (IT) service that delivers computing resources such as infrastructure as a service (IaaS), software as a service (SaaS), and platform as a service (PaaS), using the Internet anytime and anywhere (Jeong, Kim, \& Yoo, 2013) [4]. Google Cloud Platform has grown rapidly offering significant advantages and is being widely used by large and small corporate organizations to manage their IT provisions and save operating as well as IT maintenance costs (Klug \& Bai, 2015 [5]; Linthicum, 2009 [6]). Google Cloud Platform thus seems to be the most viable option for HEIs seeking efficient and economical ways to implement IT services. It helps to avoid the huge cost of maintaining and upgrading the infrastructure.

However, despite such potential and critical importance of Google Cloud Platform for HEIs, the technology is not being widely adopted by the higher education industry (Ewuzie \& Usoro, 2012 [7]; Klug \& Bai, 2015 [5]; Mircea \& Andreescu, 2011 [8]; Mustafee, 2010 [9]). Although the cloud adoption has a profound impact, research, both theoretical and empirical in this area, is limited and disorganized. Similarly, the factors affecting an organizations' reaction to Google Cloud Platform adoption hasn't been studied much (Khajeh-Hosseini, Greenwood, \& Sommerville, 2010 [10]; Klug \& Bai, 2015 [5]; Saya, Pee, \& Kankanhalli, 2010 [11]). Although a lot of models and frameworks have been proposed explaining and predicting the usage of information systems in general, there is still a dearth of knowledge regarding the factors that could affect users, to resist or reject, to use technologies such as Google Cloud Platform (V. Venkatesh \& Brown, 2001 [12]). Specifically, most of the studies have paid much attention to determine the factors responsible for technology acceptance; while neglecting the reason of resistance or rejection of individuals/organizations towards technologies, and inhibiting or discouraging factors for the same. Yet, every new technology may bring a change in the organization and users may accept or reject/resist it based on the degree of change in the enterprise culture (Joshi, 2005 [13]; Bhattacherjee \& Hikmet, 2007 [14]). Implying that if the perceptions are positive, users will most likely embrace, while as, if the perceptions are negative, user reaction would be to resist or completely reject the technology (Joshi, 1991) [15]. Thus, there is a need for more investigations aimed to ascertain why HEIs are still reluctant to use this technology despite its numerous 
benefits besides providing cost advantage. It is thus assumed that exploring HEIs decision makers' opinions relating to the adoption of Google Cloud Platform solutions might be key in increasing on the uptake of these technologies among HEIs (Yoon, Oh, \& Lee, 2013) [16]. The current paper aims to investigate factors responsible for acceptance of Google Cloud Platform and use by higher educational institutions. Specifically, this study sought to answer the following research questions:

1) What are the factors that may influence Google Cloud Platform adoption among HEIs in Malaysia?

2) What are the factors hindering Google Cloud Platform adoption among HEIs in Malaysia?

\section{Literature Review}

Every decision-making takes a rational process intended to produce a final choice that may or may not prompt action. This process requires that the decision maker puts into consideration the strengths, weakness opportunities and threats, before making a final decision. Google Cloud Platform adoption decision thus relates to organizations decision to opt for a partial or complete replacement of their incumbent systems with the cloud infrastructure. This is accomplished by leasing external computational assets. (Zhang, Cheng, \& Boutaba, 2010) [17]. The decision on whether to abandon the existing infrastructure and move to Google Cloud Platform solutions has proven to be one of those very difficult decision to make among HEIs, as can be witnessed in the slow uptake Google Cloud Platform solutions among HEIs. Basically, some studies have been conducted to explain the factors which may influence Google Cloud Platform adoption decision among HEIs. Prominent among them is Ramachandran, Sivaprakasam, Thangamani, \& Anand (2014) [18], study which proposed a novel evaluation framework to explain the decision criteria/s that should be considered in the decision making process of cloud adoption for an educational institution. They focused on factors such as Availability, Elasticity, and Scalability. On the other hand, Hsu, Ray, \& Li-Hsieh (2014) [19], developed a cloud service adoption model which highlights that perceived benefits, IT capability and external pressure are some of the main factors which might influence the decision to adopt Google Cloud Platform solutions among HEIs. While, Tashkandi \& Al-Jabri (2015) [20], argues that Relative Advantage; Compatibility; Top Management Support; Regulatory Policies; Government Pressure; and Peer Pressure were the reasons why HEIs institutions adopt Google Cloud Platform solutions in Saudi Arabia context. Likewise, Klug \& Bai (2015) [5], investigated factors responsible for adoption of Google Cloud Platform in higher educational institutions and found out that factors such as; Relative Advantage; Compatibility; Technology Readiness; Regulatory Policy; and Service Provider Support were key in influencing cloud adoption. While, Sabi, Uzoka, Langmia, \& Njeh (2016) [21] proposed a model presenting contextual, economic, and technological influences, that determine the perception towards cloud adoption at universities in 
sub-Saharan Africa. Overall the findings of a review on existing studies reveal that most studies focus on acceptance factors, with very few studies focusing on the factors which may hinder cloud adoption. This study, thus, aims to delve to determine the factors affecting Google Cloud Platform acceptance and resistance in HEIs, specifically, the information technology division managers.

\section{Methodology}

This study was aimed at understanding the factors which may influence or hinder Google Cloud Platform adoption among HEIs in Malaysia. An initial literature review on Google Cloud Platform confirmed that not much research on the factors affecting Google Cloud Platform adoption had been reported, particularly in the context of higher education institutions. The main objective of this study was to provide a priori conceptual model highlighting the factors affecting Google Cloud Platform in HEIs. Conceptual models are important especially in emerging areas which are under researched as they can provide an essential basis for theory building and further investigation (Carroll and Swatman 2000) [22]. In conducting the study, the researchers followed a case study approach, which is employees' various methods to collect data from natural settings particularly following the interpretivists paradigm. Case study research strategy is a qualitative scientific method of inquiry, which is mainly used when the researcher is interested in acquiring a deep insight into the phenomenon; or when the researcher is interested in investigating a topic which is not yet well researched (Yin, 2009) [23]. Overall, this case study is carried out to explore a particular phenomenon in a holistic manner, particularly for purposes of confirming or challenging a theory, or to explain a unique or extreme case (Yin, 2009) [23]. A case study approach was chosen for this study particularly because the context of this study, Google Cloud Platform adoption in HEIs is still under searched. In most case studies, open-ended or semi-structured, face-to-face interviews are normally used as the main method for data collection (Yin, 2009) [23]. Particularly this study used semi-structured interviews, which is a guided interview approach which helps in gaining deep understanding of certain settings, processes and relationships (Yin, 2009) [23]. In that case, a series of face-to-face interviews were conducted with 3 key informants' mainly senior IT managers who were purposively selected. Generally, these key informants were expected to have thorough knowledge regarding the IT strategies within the university. In addition, the three informs were experienced and expert in IT. The entire interview sessions were recorded using two recording devices with permission from the key informants. The interviews were later transcribed and coded, after which the themes were generated and interpreted. This process was conducted manually using templates, which had earlier been prepared for the same purpose. The findings from the interviews were complemented with data from other sources, such as the ITD website. Since the study is exploratory in nature, a conventional inductive content analysis approach was chosen. The coding categories were de- 
rived directly from the text data, without theoretical perspectives or predetermined categories (Miles and Huberman, 1994) [24]. Special attention was given to grouping the cases (based on available information) along similarities and differences of emerging themes. The details coded under each of these themes were reviewed in depth to conceptualize the factors affecting Google Cloud Platform were structured. The study adopted four-dimension criteria to assess the rigor and reliability of a large-scale qualitative research in the emergency department context. The criteria comprised strategies such as building the research team; preparing data collection guidelines; defining and obtaining adequate participation; reaching data saturation and ensuring high levels of consistency and inter-coder agreement.

Credibility and trustworthiness were strengthened by conducting multiple interviews, and by cross-checking interviews to establish a chain of evidence. It has been improved by conducting three different case studies in the current research. Reliability refers to achievement of same results, should the study be repeated. In the context of this study, a detailed case study protocol was established to enhance the reliability. The protocol provided detailed information about the concepts under investigation.

\section{Study Findings}

The findings of this study reveal a number of factors which could affect the decision to adopt Google Cloud Platform solutions. In this study these factors have been grouped into two categories; acceptance factors and resistance factors. This was intended to answer the two research questions 1) What are the factors that may influence Google Cloud Platform adoption among HEIs in Malaysia?; 2) What are the factors hindering Google Cloud Platform adoption among HEIs in Malaysia?

\section{Acceptance Factors}

Acceptance is defined as the agreement of undertaking something that is offered. It also refers to follow a course of action on a particular offering (Spanes \& Stevenson, 2005) [25]. In human psychology acceptance is a person's assent to the reality. It is either expressed explicitly or implied by conduct, presenting willingness to terms and conditions of an offer. In the context of this research, acceptance refers to the consent that has to be made before a decision to adopt Google Cloud Platform is reached. In the context of this study, Google Cloud Platform decision is treated as the acceptance to adopt Google Cloud Platform solutions, which is a decision normally taken by the change agents. A person from within or outside the organization, who helps in the organization's transformational procedure by focusing on effectiveness, improvement, and development is referred to as the change agent. Primarily, the goal of this section was to address the question: what are the factors that may influence Google Cloud Platform adoption among HEIs in Malaysia? 
Overall, four main categories of acceptance factors were identified from the interviews conducted. However, benchmarking from existing theories, e.g. the technology acceptance model, these four factors can be classified into two categories i.e. perceived ease of use and perceived usefulness. Generally, the findings of this study indicate that information technology managers, who in this case represent the change agents, can accept to adopt Google Cloud Platform solutions if they are perceived to be useful and/or perceived to be easy to use. Davis, (1989) [26], defines perceived usefulness as the user's "subjective probability that using a specific application system will increase his or her job performance". Generally, perceived usefulness refers to the attitude to the change in question. This in turn is a representation of the overall change connected to a new information system implementation, essentially comparing overall benefits and costs. Overall, perceived usefulness compares the advantages/benefits of the new implementation in terms of costs incurred. In the context of this study, perceived usefulness refers to the evaluation of changes by implementing Google Cloud Platform services. The evaluation compares benefits such as cost advantage and performance expectancy, effort expectancy and scalability (Kahneman \& Tversky, 1979) [27].

\subsection{Performance Expectancy}

Performance expectancy was the most highly cited (10 citations), with all the three interviewees mentioning this element as being key in influencing their decision.

the main factors would be in terms of managing the... our... storage right now we do have a challenge in terms of down-time due to several reasons... when we mentioned about moving to Gmail we do receive resistance from our colleagues... we do understand the concern but again I would say in case of Gmail to our experience we fell that it is better in terms of performance... in terms of... there no more downtime as before... before we have to recover our... e-mail was hacked... we took longer time to recover... compared to the one we are using right now... the Gmail... when we have problems we try to resolve at our level first... then if not resolved we go back to Gmail .. Gmail provide the... you know... then final solution.

it could be some the internal problems like most of our staff may want to upgrade their security features for our servers and that has to be done every year... and we discovered that when we upgrade the server... aah... the first attempt... they tried to upgrade there would be some problem... so they have to report back the old version of security... Perhaps if we could hire experienced organization that can handle the Google Cloud Platform environment... we would have no problems...

one of the advantages is in terms of storage... that there is now unlimited storage for the e-mail, number one; and number two even in terms of secu- 
rity is much better that can decrypt their e-mail if they feel that the e-mail need to be confidential... they have more manpower... and can be more focused looking after the interest of users...

The first element which was cited as being likely to influence Google Cloud Platform adoption is performance expectancy. Performance expectancy refers to the degree of benefits to the customers, by usage of a particular technology (Venkatesh V. T., James Y. L. and Xu, Xin, 2012) [28]. Generally, Performance Expectancy results from a user's valuation of an IT solution helping to achieve task-related objectives, such as task efficiency and effectiveness" (Dwivedi, Wade, \& Schneberger, 2011) [29]. In the context of Google Cloud Platform performance expectancy may for example, refer to the extent to which the cloud solutions can help with business process improvement (Venkatesh V. T., James Y. L. and Xu, Xin, 2012) [28]. Thus it can be deduced that:

\section{Performance expectancy is likely to positively influence Google Cloud Platform adoption among HEIs IT managers.}

\subsection{Cost Advantage}

Cost advantage was the second most cited category (8 citations), and was cited in all three interviews.

for the top management one thing that I can... I can say that if they think that if we move to this cloud environment we can save a lot in terms of money for example, then surely they will be very, very supportive. Let's say, currently, let say we spend I million for example per year, but by moving to the cloud then we can save let say $50 \%$ for example. And then tell them that the performance I think it is gonna be better for example, then I think they will be very supportive, there will be no issue from top management. Normally the top management will go into the issue of money. If they feel that the money is not a major issue. Especially now when we talk about the current economy it will be a very big objection from the university...

The second key element which can highly influence the decision to accept Google Cloud Platform solution is the cost advantage. Generally, Google Cloud Platform is believed to be one of the most cost-effective solution (Oliveira, Thomas, \& Espadanal, 2014) [30]. One key benefit of using Google Cloud Platform is that cloud solutions have the potential to reduce IT infrastructure operations and maintenance costs because consumers only pay for what they use Thus, it can be postulated that:

Cost advantage is a likely to positively influence Google Cloud Platform adoption decision among HEIs IT managers.

\subsection{Effort Expectancy}

Effort Expectancy is another important factor that influences acceptance of new 
technologies. Effort expectancy can have substantive impact on the adoption of cloud computing, with work load reduction cited seven times.

... of course we would like for go to the cloud because we want to reduce our load... our workload so that our staff can be deployed to focus on the things for example in proving services for networking... and to let our staff go into more perhaps other innovative solutions

I do not want our staff to be bogged down with routine work. To me like. with database... may be everyday someone has to make sure that the system is up... and running and have to monitor see the balancing of the servers to see that there is not... meeting maximum... you know availability with the benchmark you suddenly make it like jam... you know... so somebody has to monitor that... to me that is something very mechanical and very routine and let outsource that to other people...

I think the workload of our staff. Ok the work load of our staff I think will be reduced a lot and then, at that point I think that may be the staff can focus of doing something else. They are not going to be busy with issues like trouble-shooting or maintenance and so on... In terms of the... I think that would be what they call the immediate advantage. And then for example, for ITD for example, in a way we are sort of shortage of the manpower, so we can reduce some of the work of the staff, so we can reduce in a way... be able for them to support us a lot in other things.

Effort expectancy relates to perceived convenience or the degree of ease associated with using a system or technology. Effort expectancy is much similar to Perceived Ease of Use (PEOU) which is defined as the extent to which individuals believe that performing a behavior of interest is free of effort (Davis, 1989) [26]. PEOU is similar or opposite to (Everett M Rogers \& Shoemaker, 1971) [31] definition of complexity which they define as "the degree to which an innovation is perceived as relatively difficult to understand and use". Information systems that don't involve a lot of effort are more acceptable. Therefore, PEOU acts as a salient determinant for technology acceptance based on the aforementioned reason (Hsieh et al., 2014) [32]. According to Rogers and Shoemaker's (1971) [31], individuals are always reluctant to adopt a new innovation if they perceive that innovation to be difficult to use. In organizational settings, employees assess effort expectancy in terms of the overall simplicity or complexity associated with use of particular technologies. Many researchers conclude that effort expectancy plays a significant role in new technology adoption (Alraja, 2015) [33]. In general, individuals tend to adopt technologies that present a perceived ease of use. Thus, it can be deduced that:

Effort expectancy is likely to positively influence Google Cloud Platform adoption decision among HEIs IT managers.

\subsection{Scalability}

The forth key factor which is likely to influence Google Cloud Platform decision 
among HEIs IT managers is scalability. Maintenance and scalability are two key issues surrounding traditional legacy systems supporting core IT processes of an organization (Khadka, Saeidi, Idu, Hage, \& Jansen, 2012) [34]. Thus, cloud technologies pay-per-use model is the central attraction for its adoption, offering scalability and interoperability features (Rai, Sahoo, \& Mehfuz, 2015) [35]. Google Cloud Platform facilitates rapid and automated computing and storage resource provisioning. It also enhances the ability to add resources such as additional storage, network bandwidth, memory, and computing power as required to cater for the load surges (Kshetri, 2010) [36]. Such resource elasticity supports the promise of on-demand computing power and, therefore, flexible response to change (Carcary et al., 2014) [37]. Scalability of Google Cloud Platform significantly reduces the resources idle time. Thereby, helping organizations to only use the required resources and instant scale up when the requirements increase (Marston, Li, Bandyopadhyay, Zhang, \& Ghalsasi, 2011) [38]. Thus it can be posited that:

\section{Scalability is likely to positively influence Google Cloud Platform adoption decision among HEIs IT managers.}

\section{Technology Acceptance: Theoretical Foundation}

The findings of this study are in tandem with prior studies. Researches investigating acceptance of technology have been vital for the last two decades. Along this line, researchers have adopted diverse conceptual, theoretical, and analytic approaches and employed various empirical methodologies at multiple levels in explaining the factors affecting the diffusions of innovations in general and technology adoption in particular (Lee \& Xia, 2006) [39]. At a firm level a number of theories on technology acceptance and/or diffusion of innovation have been widely applied to studies investigation adoption and diffusion of innovation. Popular models which have been widely adopted by the IS researchers in explaining the critical factors which could influence information systems acceptance include the diffusion of innovation theory (Rogers, 2003) [40]; the technology acceptance model (Davis, 1989) [26], and the technological, organizational, and environmental model (Tornatzky, Fleischer, \& Chakrabarti, 1990) [41]. The Diffusion of Innovation (DOI) theory was one of the seminar works introduced by Rogers in 2003 to explain a new idea or technology spread out in a social system (Everett M. Rogers, 2003) [40]. Rogers (2003) [40] defines diffusion as the process by which an innovation is communicated through certain channels over time among the members of a social system. The Technology-Organization-Environment Framework (TOE), is another popular model among IS researchers, representing the influence of firm context on adoption and implementation of innovations (Baker, Al-Gahtani, \& Hubona, 2011) [42]. In consistency with Rogers' arguments, Tornatzky et al. (1990) [41] argue that the contextual factors of adopting an IT innovation are threefold, including technological context, organizational context, and external environment context 
(Tornatzky et al., 1990) [41]. According to (Tornatzky et al., 1990) [41], these three contexts present opportunities for technological innovation. However, the finding or this study is much related to the factors presented by the Technology Acceptance Model (TAM), which was proposed by (Davis, 1985) [43]. TAM is one of the leading IS model used in explaining and predicting the acceptance and use of a system. Technology acceptance model (TAM) was developed by Davis et al. (1989) [26] relying on two theories; expectancy-value (Fishbein \& Ajzen, 1975) [44] and reasoned action (TRA) (Ajzen \& Fishbein, 1980) [45]. The expectancy-value theory indicates that individuals are affected by expected outcomes and associated values as key factors in choosing behaviors. (Borders, Earleywine, \& Huey, 2004) [46]. On the other hand, the theory of reasoned action (TRA) explains the determinants of consciously intended behaviors (Ajzen \& Fishbein, 1980 [45]; Fishbein \& Ajzen, 1975 [44]). The TRA posits that "a person's performance of a specific behavior is determined by his or her behavior intention to perform the behavior" (Davis, 1989) [26]. Based on these two theories, Davis suggests that the intention to use a particular technology is often influenced by two factors, perceived ease of use (PEOU) and perceived usefulness (PU). If the perceived value of the change is higher, then individuals are most likely to support the change. Likewise, low value indicates greater resistance (Hsieh, Lai, \& Ye, 2014 [32]; Liu, Sia, \& Wei, 2008 [47]; V. Venkatesh et al., 2003 [48]). Generally, a number of studies have adopted these models in trying to examine the validity of these relationships on various technologies, and specifically on Google Cloud Platform acceptance. Thus this study also benchmarks from TAM to validate and position the findings from this exploratory study.

\section{Compatibility}

... we have trust issues with the organization who provide Google Cloud Platform because normally they have their own ethics that we have to follow... we are talking just about having infrastructure connected to the Google Cloud Platform environment and it depends much on our network bandwidth... so our new bandwidth I know is about 3.4 I think gigabyte 3 or 4 gigabyte and in terms of the speed would be good enough...

Compatibility refers to reconcilability of existing values, behavioral patterns, and experiences of an organization and its employees pertaining to a new technology or innovation (Oliveira et al., 2014) [30]. In the context of cloud computing, compatibility takes into account the convenience of system integration and customization or adjustment of services (Gangwar, Date, \& Ramaswamy, 2015) [49]. Studies indicate that compatibility is most likely to be considered during pre-adoption (Wisdom, Chor, Hoagwood, \& Horwitz, 2014) [50]. A technology inferred to be compatible with the work systems has higher chances of organizational adoption (Low, Chen, \& Wu, 2011) [51]. Google Cloud Platform allows organizations to remain at the cutting edge of technology without affecting cur- 
rent legacy IT systems in-line with their organizational, managerial and operational needs (Gupta, Seetharaman, \& Raj, 2013 [52]; Gutierrez, Boukrami, \& Lumsden, 2015 [53]; Sultan, 2011 [54]).

\section{Resistance Factors}

Resistance involves two components; first, resisting an action or effect and second, conscious attempt to avoid the system or change (Cenfetelli, 2004) [55]. In Information Systems research, resistance has been seen as adverse reaction or user opposition to a perceived change involving a new implementation or innovation (Hirschheim \& Newman, 1988 [56]; Markus, 1983 [57]). Normally, when considering whether to adopt a new innovation or technologies, there are always resistance factors which may lead to rejection of the innovation or technology (Marakas \& Hornik, 1996) [58]. Resistance behaviors could vary from lack of cooperation (Marakas \& Hornik, 1996) [58], to sabotage (Carnall, 1986) [59]. The findings of this study indicate that these factors are defined in terms of loss aversion, concerns relating to vendor reliability, psychological commitment and concerns relating to the lack of a regulatory policy.

\subsection{Loss Aversion}

...you want to do something where everything is within our control... so we build our own data center... we build our own... you know... our own cable backbone... aah we provide almost everything... computing equipment... when everything is within our control, then we know what are the critical time... because we know... what are the patterns... being used... for example during the semester when there are registration period... so you require a lot of resources... so let's say if you put things all to the cloud... can the cloud facilitate... or adapt to this kind of requirement... would it have the flexibility... so those are the things that are... let say... aah... when you put things in the cloud... you still have that full control or do we have to... you know... let go some of the control to the third party... and what would be the impact to the current service...

so aah compliance to the established standards is one of the things that you have to look at... within all of our applications, our architecture based on the industry standards and based on the standards being adopted by you know... so let's say if your organization's business process is a proprietary one, you know something that you develop is based on your own unique requirements so you cannot... leverage on those systems that have already been built on industry best practices... so in other words, it is not just the applications per se, but you may have to also look at your current business processes as well as your current business models.

... the concern of some of the technical staff... concerned about losing control... aah it is just like to me we are doing outsourcing for software and development... we outsource it to a company India or outside Malaysia... 
aah in a way we do lose some control because the source code... you know... they have the source code and they can do whatever manipulation if they want...

Loss aversion is a commonly discussed issue in cloud computing. Polites \& Karahanna (2012) [60] define loss aversion as the user attachment and resolve in using a legacy information system, when better alternatives or incentives to change exist. In decision theories, most studies suggest that losses are twice as powerful, psychologically, as gains. Thus people value the current product and services than the alternatives due to loss aversion (Tversky \& Kahneman, 1991) [61]. Markus (1983) [57] explains that cognitive misperceptions relating to loss of power can lead to user resistance. Users tend to determine their work situation leading to status quo bias. Therefore, they tend not to switch to unfamiliar environment or operating procedures, in the fear of losing control (Samuelson \& Zeckhauser, 1988) [62]. Thus it can be deduced that:

Loss aversion is likely to negatively impact on Google Cloud Platform adoption decision among HEIs IT managers.

\subsection{Vendor Reliability}

...our concern about security... it is just like the same thing when we implemented our e-mail... we are using the Gmail for all our staff we do receive some resistance from staff because that say about this confidentiality of the e-mail. Security of e-mail... they do not trust outsiders to look-up their e-mail.

when your things or your resources are within your premise... your premises... you have full control of the security... there are security issues... but when you put it in the cloud there are also security issues, especially privacy...

I think the security issue is very critical reason that they consider when we want to move everything to the cloud environment... why don't we put our documents to the cloud and subscribe to some cloud provider... why this for example one of the first question they put up this is, it secure... ok... how secure is the document when we put it online... in terms of our confidential documents, confidential data, surely we are not going to... for me personally I think aaah we are not going to put up there... the lifespan of the provider. Ok, so some... some say that ok, if we put it up and then suddenly the provider... for example stop the business.

I think the brand name of the company will bring and impact... ok... for example, ... like Google for example, we see the future of Google but again for example, previously I think a few years back, ten years ago we talked about... everyone talked about yahoo. For example, and then aaa we consider yahoo it quite a big name in the ICT environment but now days it is gone. Now we talking about Google for example...

Yes the private cloud is one that I think can basically... aaah in a way re- 
duce the trust issues among the users... if we are talking about the private cloud, and then the users, I think they are quite in a way... aah open to go and then aah put everything I mean the documents and whatever data that we have so the private cloud I think can be sort of aah provide a new room that can attract rather that's...

... we cannot simply just put $100 \%$ trust to the Google Cloud Platform provider... they may say that you know some of our information may be shared with other parties... unless if we do our own auditing so that it will be done properly...

Vendor Reliability refers to issues such as privacy, confidentiality, service availability data transmission security and data storage security (Subashini \& Kavitha, 2011 [63]; Khan, Zhang, Khan, \& Chen, 2011 [64]; Zhang et al., 2010 [17]; Kim, 2011 [65]). Storage of data with a third party raises many concerns such as loss of confidentiality, theft, loss of data and most importantly data ownership (Oliveira et al., 2014 [30]; Subashini \& Kavitha, 2011 [63]). Furthermore, geographical location of the data centers is a critical consideration due to difference in privacy and data protection laws (Brender and Markov, 2013) [66]. Although a good Service Level Agreement with clear standard rules and policies regarding the format of data can significantly reduce the risk of customer lock-in; however clients are still not convinced given the fact that some of the cloud solutions are provided by vendors who reside on a different content, and when they shut down their business, it is not always easy to trace them. Thus, it can be posited that:

Vendor reliability is likely to negatively impact on Google Cloud Platform adoption decision among HEIs IT managers.

\subsection{Lack of Regulatory Policy}

...if there is a sort of directive coming from the ministry for example... as university... for example you have to go to Google Cloud Platform environment and everything, I think they will always be a possibility...

Lack of stringent regulatory policies can retard innovation in numerous industries. Generally, prior researchers have noted that laws and regulations are among the major factors influencing the diffusion of clouds. When there are no clear government regulations and explicit regulative processes which would regulate cloud providers it may not be easy for potential clients to trust and later alone do business with cloud providers (Kshetri, 2016) [67]. Thus it can be deduced that:

Lack of regulatory policy is likely to negatively impact on Google Cloud Platform adoption decision among HEIs IT managers.

\section{Psychological Commitment}

... what will happen to our existing systems... for example in the context of 
this university we have quite a good data center in a way, with a good technology over there, so what are we going to do with that investment...

Sunk costs... we have not been... actually been approached by any companies that can provide Google Cloud Platform option that is considered to be within our budget... most of the options given so far is to use... is quiet too big the budget for the university... our technical team may not have much objection on that unless for the amount of charges... Also talking about private. Kind of Google Cloud Platform facility but I do believe there will be a structure for that unless it is private but there must be something and a cost that they have to incur...and they may charge back to us as the customers... If may be they can buddle-up with the internet provider like TIME or other big players perhaps they can provide more discounted kind of price for their customers like the universities...

We want a database company which is willing to give us a good price... for example, we submitted a similar proposal to have one centralized database within Oracle... we sent to the ministry of HE but it was rejected... it was rejected... one of the reasons that was considered was that the amount was too huge...

Adopting cloud systems entails a very difficult decision regarding the discontinuation of current, on-premises systems (Gill, 2011 [68]; Mell \& Grance, 2011 [69]). Psychological commitment relates to previous commitments, which cause reluctance to switch to a new alternative. The main factors that contribute to psychological commitment include worries concerning uncertainty costs and loss of control (Samuelson and Zeckhauser 1988) [62]. The fear of losing control is one of the biggest worries for the IT professionals when it comes to acceptance of new innovations such as cloud computing. Efforts to feel in control stem from individuals' desires to direct or determine their own situation (Samuelson and Zeckhauser 1988) [62]. Users tend to determine their work situation leading to status quo bias. Therefore, they tend not to switch to an unfamiliar environment or operating procedures, in the fear of losing control. Generally, perceived loss of control is big concern to those intending to adopt Google Cloud Platform since applications and services will run remotely on third party environments. This limits user control over the functionality and execution of the system; hardware and software alike (Gutierrez et al., 2015) [53]. Primarily, the IT departments might not want to give away some of their powers to a third party, especially for those enterprises that are used to the traditional on-premises approach where they have full control over their data (Rania Fahim El-Gazzar, 2014) [70]. Usage of products/services for prolonged periods decreases the willingness to change, even for better alternatives (Samuelson \& Zeckhauser, 1988) [62]. Thus, it can be argued that:

Psychological Commitment is likely to negatively influence Google Cloud Platform decisions among HEIs IT managers. 


\section{User Resistance: Theoretical Foundations}

The factors which could influence negative reactions towards acceptance of new innovations such as Google Cloud Platform can be traced to the status quo bias theory (SQB). The SQB theory provides a set of useful theoretical explanations for understanding people's preference to maintain their current status or situation (Samuelson \& Zeckhauser, 1988) [62]. According to (Samuelson \& Zeckhauser, 1988) [62], every decision has a status quo option. This acts a strong detriment to alternatives influencing the final decision. Users tend to act conservatively to maintain the traditional workflow to avoid any possible risks (Luo, $\mathrm{Li}$, Zhang, \& Shim, 2010) [71]. This type of behavior is normally attributed to cognitive misconceptions and loss aversion, which in this study have also been found to have a strong negative impact on the IT managers behavior intention to adopt Google Cloud Platform solutions (Kahneman \& Tversky, 1979) [27].

\section{Mediating Effect of Organizational Support}

A mediating factor is a variable that accounts for the relationship between the independent factors and the criterion measure. Generally, a mediation effect is said to occur when a causal effect of a given independent variable $(\mathrm{X})$ on a dependent variable $(\mathrm{Y})$ is found to have a partial or full intervention from another intervening variable (M) (Kenny, 1986; Rucker, 2011). Basically, the findings of this study reveal that organizational support, in terms of employee support and top management support plays a key mediation role in the relationships between acceptance factors and resistance factors. In other words, organizational support is a key predictor of technology adoption decisions, which is normally dependent upon the employees and top management conviction of the relative advantage of the new innovations, as well as the related opportunity cost. According to a number of researchers (Ewuzie \& Usoro, 2012 [7]; Klug \& Bai, 2015 [5]; Mircea \& Andreescu, 2011 [8]; Mustafee, 2010 [9]; Vakil, Lu, \& Russakoff, 2012 [72]; Yoon et al., 2013 [16]), a lack of organizational support in terms of employee support and top management support is one of the main reasons for the slow adoption of Google Cloud Platform is that HEIs. Basically, top management support is an extremely important factor for overcoming internal barriers and resistance to change for anyone seeking to implement new innovations (Low et al., 2011) [51]. Just like with any other innovation, Google Cloud Platform adoption requires total support of the top management. Typically cloud implementation involves resource and activity integration and process re-engineering (Gutierrez et al., 2015 [53]; Wisdom et al., 2014 [50]). Therefore, involvement of the management ensures resource allocation for the new technology adoption and a formal articulated vision for the organizational change, stressing the importance of the new technology (Thong, 1999; Low et al., 2011 [51]). An organizational context for fostering innovation that welcomes change can only be designed and implemented by the top management. It is also important that the implementation of new system or technology receives the bracing of all em- 
ployees, especially because it is the employees who use the new systems or technology. Generally, when employees are not supportive of the new technology, the organization is most likely not to introduce that technology (Daylami et al., 2005) [73]. In many cases, when employees are not supportive of the new innovations they tend to engage in several resistance behaviors such as passive resistance, covert resistance and possibly active sabotage of the implementation effort (Marakas and Hornik 1996 [58]; Markus 1983 [57]). Thus it can be deduced that:

\section{Organizational support mediates in the relationship between accep- tance factors and resistance factors.}

\section{Organizational Support: Theoretical Foundations}

The element of organizational support, one of the key factors playing role in technology acceptance can be traced back to the theory of reasoned action (TRA). The TRA specifies that individual behavioral intention is a function of two determinants: attitude towards behavior, and a person's perception of social pressures termed subjective norm (Fishbein \& Ajzen, 1975) [44]. Subjective norm is influenced by a set of beliefs termed normative beliefs normative beliefs, which "are concerned with the likelihood that important referent individuals or groups would approve or disapprove of performing the behavior" (Ajzen \& Madden, 1986) [74]. In organization context, these groups may include top management, employee and other groups from whom one must first win their bracing in order to introduce new innovations.

\section{The Derived Conceptual Model}

Based on the discussion above, a conceptual model has been derived which indicates that acceptance factors in terms of performance expectancy, effort expectancy, cost advantage and scalability are likely to positively influence Google Cloud Platform adoption decisions among HEIs IT managers. On the other hand, resistance factors in terms of loss aversion, psychological commitment, concerns relating to vendor reliability and lack of regulatory policy are likely to negatively impact on the Google Cloud Platform adoption decision among HEIs IT managers. Whereas, organizational support is likely to mediate in the relationship between acceptance factors and resistance factors. Based on these findings the following conceptual model (Figure 1) has been derived.

\section{Conclusions and Future Research}

The growing needs for information technology and reduced IT budgets are posing a lot of difficulties for higher educational institutions in providing necessary information technology support for administrative, educational and research activities (Sife et al., 2007) [2]. Google Cloud Platform offers an effective model for reducing IT cost, while providing higher levels of process performance. Despite 


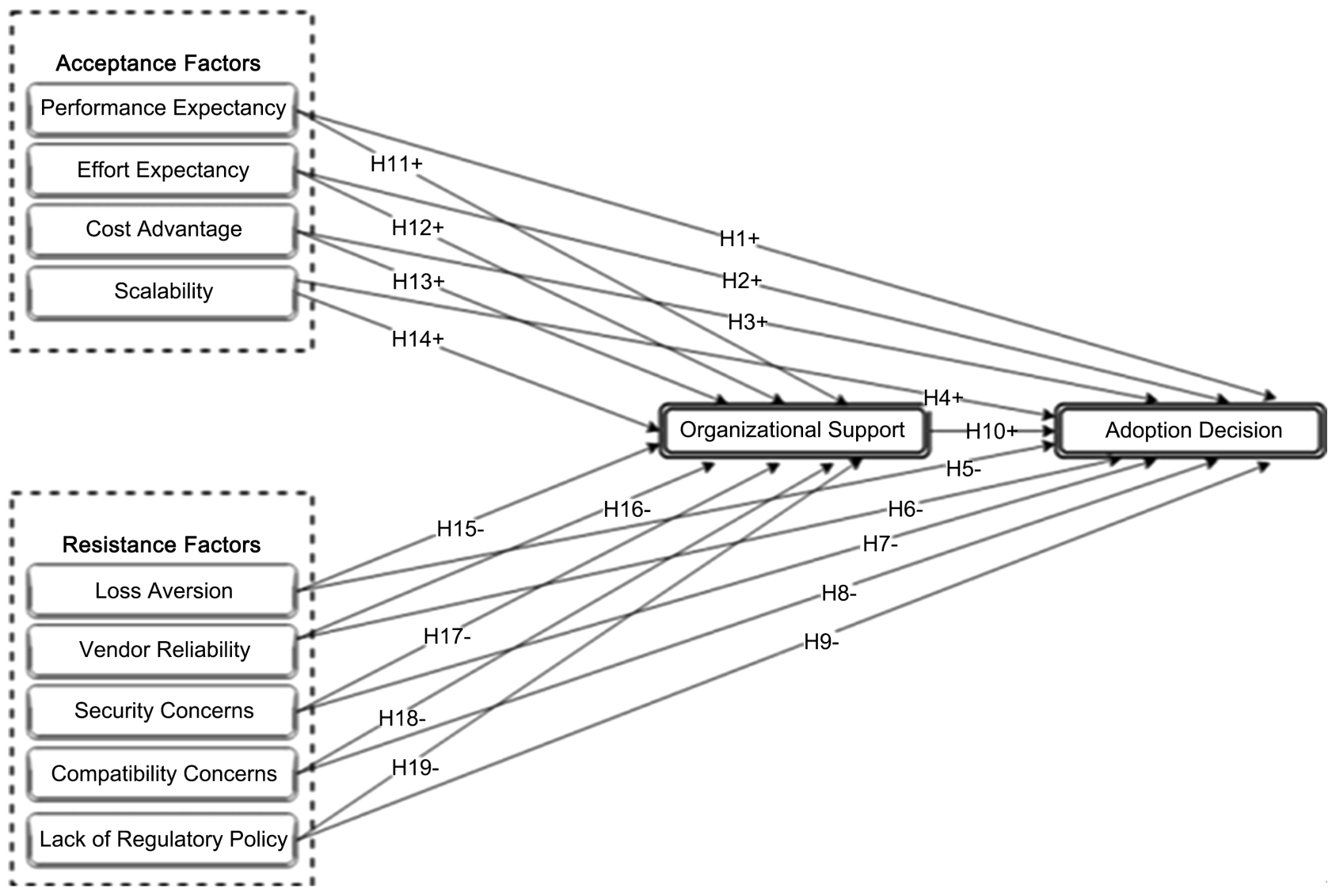

Figure 1. The research framework.

its importance, the uptake of Google Cloud Platform is still very low especially among HEIs in developing economies like Malaysia. Several studies have been conducted concerned with assessing the factors which positively influence acceptance of Google Cloud Platform adoption, each bringing its own theoretical and empirical perspective to bear upon the question of technology acceptance. However, there is still lack of research to explain why HEIs are reluctant to implement Google Cloud Platform solutions. Thus, the low uptake of Google Cloud Platform among HEIs could to some extent be attributed to the general lack of such research which could have drawn some insights on why IT managers decide to maintain their status quo instead of harnessing the potential benefits of the cloud environment. This study sought to address this critical gap by proposing a model which highlights eight key factors that are key in influencing adoption decisions. A systematic review of prior studies indicates that similar studies handle the issues of acceptance and rejection separately, thus it is assumed that integration of both acceptance factors and resistance factors into a unified theoretical model not only is a unique approach, but also likely yields the greatest contribution to this particular knowledge domain. Particularly, the findings of this study indicate that factors such as performance expectancy, effort expectancy, and scalability and cost advantage will positively influence IT managers to accept Google Cloud Platform solutions. While factors such as 
psychological commitment, loss aversion, concerns about vendor reliability and lack of regulatory policy are still hindering Google Cloud Platform adoption among HEIs.

The findings of this study are intended to provide some insights to the cloud vendor on what they might need to change in order to tap into the prospective market of HEIs institutions, which still seem to be a bit reluctant to move to the cloud environment. This study is also meant to help the policy makers to understand the key factors which need to be addressed in order to increase the uptake of Google Cloud Platform solutions as one of the measures to reduce the IT costs, especially at this critical moment when the economy is struggling. The study used face-to-face interviews with IT managers from selected HEIs. Although this approach provides rich insights, it cannot be generalized because only a few managers were approached. Thus, further research is expected to benchmark the derived model, and try to empirically validate it. Generally, the research agenda resulting from study relates to each of the two research questions. However, although a great deal of research has examined the acceptance factors, question two which relates to the factors that could hinder adoption remains relatively understudied. Much work remains to uncover that factors have a more significant negative effect on cloud adoption decision.

\section{Conflicts of Interest}

The authors declare no conflicts of interest regarding the publication of this paper.

\section{References}

[1] Ayyad, F. (2015) Higher Education and Privilege: 21st Century Issues [Special Section]. College Student Affairs Leadership, 2, 2.

[2] Sife, A., Lwoga, E. and Sanga, C. (2007) New Technologies for Teaching and Learning: Challenges for Higher Learning Institutions in Developing Countries. International Journal of Education and Development Using ICT, 3, 57-67.

[3] Dominguez, A. (2013) Evaluating the Acceptance of Cloud-Based Productivity Computer Solutions in Small and Medium Enterprises. Capella University, Minneapolis.

[4] Jeong, J.-S., Kim, M. and Yoo, K.-H. (2013) A Content Oriented Smart Education System Based on Cloud Computing. International Journal of Multimedia and Ubiquitous Engineering, 8, 313-328. https://doi.org/10.14257/ijmue.2013.8.6.31

[5] Klug, W. and Bai, X. (2015) Factors Affecting Google Cloud Platform Adoption among Universities and Colleges in the United States and Canada. Issues in Information Systems, 16, No. 3.

[6] Linthicum, D.S. (2009) Google Cloud Platform and SOA Convergence in Your Enterprise: A Step-by-Step Guide. Pearson Education, 264 p.

[7] Ewuzie, I. and Usoro, A. (2012) Exploration of Google Cloud Platform Adoption for e-Learning in Higher Education. 2012 2nd Symposium on Network Google Cloud Platform and Applications, London, 3-4 December 2012.

https://doi.org/10.1109/NCCA.2012.19 
[8] Mircea, M. and Andreescu, A.I. (2011) Using Google Cloud Platform in Higher Education: A Strategy to Improve Agility in the Current Financial Crisis. Communications of the IBIMA, 2011, Article ID: 875547. https://doi.org/10.5171/2011.875547

[9] Mustafee, N. (2010) Exploiting Grid Computing, Desktop Grids and Google Cloud Platform for e-Science: Future Directions. Transforming Government. People, Process and Policy, 4, 288-298. https://doi.org/10.1108/17506161011081291

[10] Khajeh-Hosseini, A., Greenwood, D. and Sommerville, I. (2010) Cloud Migration: A Case Study of Migrating an Enterprise IT System to IaaS. 2010 IEEE 3rd International Conference on Cloud Platform, Miami, 5-10 July 2010. https://doi.org/10.1109/CLOUD.2010.37

[11] Saya, S., Pee, L.G. and Kankanhalli, A. (2010) The Impact of Institutional Influences on Perceived Technological Characteristics and Real Options in Google Cloud Platform Adoption. ICIS 2010 Proceedings, St. Louis, 15-18 December 2010.

[12] Venkatesh, V. and Brown, S.A. (2001) A Longitudinal Investigation of Personal Computers in Homes: Adoption Determinants and Emerging Challenges. MIS quarterly, 25, 71-102. https://doi.org/10.2307/3250959

[13] Joshi, K. (2005) Understanding User Resistance and Acceptance during the Implementation of an Order Management System: A Case Study Using the Equity Implementation Model. Journal of Information Technology Case and Application Research, 7, 6-20. https://doi.org/10.1080/15228053.2005.10856057

[14] Bhattacherjee, A. and Hikmet, N. (2007) Physicians' Resistance toward Healthcare Information Technology: A Theoretical Model and Empirical Test. European Journal of Information Systems, 16, 725-737. https://doi.org/10.1057/palgrave.ejis.3000717

[15] Joshi, K. (1991) A Model of Users' Perspective on Change: The Case of Information Systems Technology Implementation. MIS Quarterly, 15, 229-242. https://doi.org/10.2307/249384

[16] Yoon, Y.B., Oh, J. and Lee, B.G. (2013) The Establishment of Security Strategies for Introducing Cloud Computing. TIIS, 7, 860-877.

https://doi.org/10.3837/tiis.2013.04.015

[17] Zhang, Q., Cheng, L. and Boutaba, R. (2010) Cloud Computing: State-of-the-Art and Research Challenges. Journal of Internet Services and Applications, 1, 7-18. https://doi.org/10.1007/s13174-010-0007-6

[18] Ramachandran, N., Sivaprakasam, P., Thangamani, G. and Anand, G. (2014) Selecting a Suitable Cloud Computing Technology Deployment Model for an Academic Institute. Campus-Wide Information Systems, 31, 319-345.

[19] Hsu, P.F., Ray, S. and Li-Hsieh, Y.Y. (2014) Examining Cloud Computing Adoption Intention, Pricing Mechanism, and Deployment Model. International Journal of Information Management, 34, 474-488.

https://doi.org/10.1016/j.ijinfomgt.2014.04.006

[20] Tashkandi, A. and Al-Jabri, I. (2015) Cloud Computing Adoption by Higher Education Institutions in Saudi Arabia: Analysis Based on TOE. 2015 International Conference on Cloud Computing (ICCC), Riyadh, 26-29 April 2015, 1-8. https://doi.org/10.1109/CLOUDCOMP.2015.7149634

[21] Sabi, H.M., Uzoka, F.M.E., Langmia, K. and Njeh, F.N. (2016) Conceptualizing a Model for Adoption of Cloud Computing in Education. International Journal of Information Management, 36, 183-191. https://doi.org/10.1016/j.ijinfomgt.2015.11.010 
[22] Carroll, J.M. and Swatman, P.A. (2000) Structured-Case: A Methodological Framework for Building Theory in Information Systems Research. European journal of information systems, 9, 235-242. https://doi.org/10.1057/palgrave.ejis.3000374

[23] Yin, R.K. (2009) Case Study Research: Design and Methods. Sage, Thousand Oaks.

[24] Miles, M.B. and Huberman, A.M. (1994) Qualitative Data Analysis: An Expanded Sourcebook. Sage, Thousand Oaks.

[25] Spanes, C. and Stevenson, A. (2005) Oxford Dictionary of English. Oxford University Press, New York.

[26] Davis, F.D. (1989) Perceived Usefulness, Perceived Ease of Use, and User Acceptance of Information Technology. MIS Quarterly, 13, 319-340. https://doi.org/10.2307/249008

[27] Kahneman, D. and Tversky, A. (1979) Prospect Theory: An Analysis of Decision under Risk. Econometrica: Journal of the Econometric Society, 47, 263-291. https://doi.org/10.2307/1914185

[28] Venkatesh, V.T., James Y.L. and Xu, X. (2012) Consumer Acceptance and Use of Information Technology: Extending the Unified Theory of Acceptance and Use of Technology. MIS Quarterly, 36, 157-178. https://doi.org/10.2307/41410412

[29] Dwivedi, Y.K., Wade, M.R. and Schneberger, S.L. (2011) Information Systems Theory: Explaining and Predicting Our Digital Society. Springer, New York. https://doi.org/10.1007/978-1-4419-9707-4

[30] Oliveira, T., Thomas, M. and Espadanal, M. (2014) Assessing the Determinants of Google Cloud Platform Adoption: An Analysis of the Manufacturing and Services Sectors. Information \& Management, 51, 497-510.

https://doi.org/10.1016/j.im.2014.03.006

[31] Rogers, E.M. and Shoemaker, F.F. (1971) Communication of Innovations: A Cross-Cultural Approach. The Free Press, New York.

[32] Hsieh, P.-J., Lai, H.-M. and Ye, Y.-S. (2014) Patients' Acceptance and Resistance toward the Health Cloud: An Integration of Technology Acceptance and Status Quo Bias Perspectives. Management Science, 40, 40-465.

[33] ALraja, M.N. and Aref, M. (2015) Customer Acceptance of e-Commerce: Integrating Perceived Risk with TAM. International Journal of Applied Business and Economic Research, 13, 913-921.

[34] Khadka, R., Saeidi, A., Idu, A., Hage, J. and Jansen, S. (2012) Legacy to SOA Evolution: Evaluation Results. Technical Report UU-CS-2012-006, Utrecht University, Utrecht.

[35] Rai, R., Sahoo, G. and Mehfuz, S. (2015) Exploring the Factors Influencing the Google Cloud Platform Adoption: A Systematic Study on Cloud Migration. Springerplus, 4, 197. https://doi.org/10.1186/s40064-015-0962-2

[36] Kshetri, N. (2010) Cloud Computing in Developing Economies. Computer, 43, 47-55. https://doi.org/10.1109/MC.2010.212

[37] Carcary, M., Doherty, E., Conway, G. and McLaughlin, S. (2014) Google Cloud Platform Adoption Readiness and Benefit Realization in Irish SMEs-An Exploratory Study. Information Systems Management, 31, 313-327.

https://doi.org/10.1080/10580530.2014.958028

[38] Marston, S., Li, Z., Bandyopadhyay, S., Zhang, J. and Ghalsasi, A. (2011) Cloud Computing-The Business Perspective. Decision support systems, 51, 176-189. https://doi.org/10.1016/j.dss.2010.12.006

[39] Lee, G. and Xia, W. (2006) Organizational Size and IT Innovation Adoption: A Me- 
ta-Analysis. Information \& Management, 43, 975-985. https://doi.org/10.1016/j.im.2006.09.003

[40] Rogers, E.M. (2003) Diffusion of Innovations. 5th Edition, Free Press, New York.

[41] Tornatzky, L.G., Fleischer, M. and Chakrabarti, A.K. (1990) Processes of Technological Innovation. Lexington Books, Lexington.

[42] Baker, E.W., Al-Gahtani, S. and Hubona, G.S. (2011) Cultural Impacts on Acceptance and Adoption of Information Technology in a Developing Country. In: Tan, F.B., Ed., International Comparisons of Information Communication Technologies. Advancing Applications: Advancing Applications, IGI Global, 54-77. https://doi.org/10.4018/978-1-61350-480-2.ch003

[43] Davis, F.D. (1985) A Technology Acceptance Model for Empirically Testing New End-User Information Systems: Theory and Results. Massachusetts Institute of Technology, Cambridge, MA.

[44] Fishbein, M. and Ajzen, I. (1975) Belief, Attitudes, Intention, and Behavior. An Introduction to Theory and Research. Addison-Wesley, Reading, MA.

[45] Ajzen, I., et al. (1980) Understanding Attitudes and Predicting Social Behaviour. Prentice Hall PTR, Englewood Cliffs.

[46] Borders, A., Earleywine, M. and Huey, S.J. (2004) Predicting Problem Behaviors with Multiple Expectancies: Expanding Expectancy-Value Theory. Adolescence, 39, 539.

[47] Liu, C., Sia, C.-L. and Wei, K.-K. (2008) Adopting Organizational Virtualization in B2B Firms: An Empirical Study in Singapore. Information \& Management, 45, 429-437. https://doi.org/10.1016/j.im.2008.06.005

[48] Venkatesh, V., Morris, M.G., Davis, G.B. and Davis, F.D. (2003) User Acceptance of Information Technology: Toward a Unified View. MIS Quarterly, 27, 425-478. https://doi.org/10.2307/30036540

[49] Gangwar, H., Date, H. and Ramaswamy, R. (2015) Understanding Determinants of Google Cloud Platform Adoption Using an Integrated TAM-TOE Model. Journal of Enterprise Information Management, 28, 107-130. https://doi.org/10.1108/JEIM-08-2013-0065

[50] Wisdom, J.P., Chor, K.H.B., Hoagwood, K.E. and Horwitz, S.M. (2014) Innovation Adoption: A Review of Theories and Constructs. Administration and Policy in Mental Health and Mental Health Services Research, 41, 480-502. https://doi.org/10.1007/s10488-013-0486-4

[51] Low, C., Chen, Y. and Wu, M. (2011) Understanding the Determinants of Google Cloud Platform Adoption. Industrial Management \& Data Systems, 111, 1006-1023. https://doi.org/10.1108/02635571111161262

[52] Gupta, P., Seetharaman, A. and Raj, J.R. (2013) The Usage and Adoption of Google Cloud Platform by Small and Medium Businesses. International Journal of Information Management, 33, 861-874. https://doi.org/10.1016/j.ijinfomgt.2013.07.001

[53] Gutierrez, A., Boukrami, E. and Lumsden, R. (2015) Technological, Organisational and Environmental Factors Influencing Managers' Decision to Adopt Google Cloud Platform in the UK. Journal of Enterprise Information Management, 28, 788-807. https://doi.org/10.1108/JEIM-01-2015-0001

[54] Sultan, N.A. (2011) Reaching for the "Cloud": How SMEs Can Manage. International Journal of Information Management, 31, 272-278. https://doi.org/10.1016/j.ijinfomgt.2010.08.001

[55] Cenfetelli, R.T. (2004) Inhibitors and Enablers as Dual Factor Concepts in Tech- 
nology Usage. Journal of the Association for Information Systems, 5, 16. https://doi.org/10.17705/1jais.00059

[56] Hirschheim, R. and Newman, M. (1988) Information Systems and User Resistance: Theory and Practice. The Computer Journal, 31, 398-408. https://doi.org/10.1093/comjnl/31.5.398

[57] Markus, M.L. (1983) Power, Politics, and MIS Implementation. Communications of the ACM, 26, 430-444. https://doi.org/10.1145/358141.358148

[58] Marakas, G.M. and Hornik, S. (1996) Passive Resistance Misuse: Overt Support and Covert Recalcitrance in IS Implementation. European Journal of Information Systems, 5, 208-219. https://doi.org/10.1057/ejis.1996.26

[59] Carnall, C.A. (1986) Toward a Theory for the Evaluation of Organizational Change. Human Relations, 39, 745-766. https://doi.org/10.1177/001872678603900803

[60] Polites, G.L. and Karahanna, E. (2012) Shackled to the Status Quo: The Inhibiting Effects of Incumbent System Habit, Switching Costs, and Inertia on New System Acceptance. MIS Quarterly, 36, 21-42. https://doi.org/10.2307/41410404

[61] Tversky, A. and Kahneman, D. (1991) Loss Aversion in Riskless Choice: A Reference-Dependent Model. The Quarterly Journal of Economics, 106, 1039-1061. https://doi.org/10.2307/2937956

[62] Samuelson, W. and Zeckhauser, R. (1988) Status Quo Bias in Decision Making. Journal of Risk and Uncertainty, 1, 7-59. https://doi.org/10.1007/BF00055564

[63] Subashini, S. and Kavitha, V. (2011) A Survey on Security Issues in Service Delivery Models of Cloud Computing. Journal of Network and Computer Applications, 34, 1-11. https://doi.org/10.1016/j.jnca.2010.07.006

[64] Khan, F., Zhang, B., Khan, S. and Chen, S. (2011) Technological Leap Frogging e-Government through Cloud Computing. 2011 4th IEEE International Conference on Broadband Network and Multimedia Technology (IC-BNMT), Shenzhen, 28-30 October 2011. https://doi.org/10.1109/ICBNMT.2011.6155925

[65] Kim, W. (2011) Google Cloud Platform Adoption. International Journal of Web and Grid Services, 7, 225-245. https://doi.org/10.1504/IJWGS.2011.043529

[66] Brender, N. and Markov, I. (2013) Risk Perception and Risk Management in Cloud Computing: Results from a Case Study of Swiss Companies. International Journal of Information Management, 33, 726-733. https://doi.org/10.1016/j.ijinfomgt.2013.05.004

[67] Kshetri, N. (2016) Institutional and Economic Factors Affecting the Development of the Chinese Google Cloud Platform Industry and Market. Telecommunications Policy, 40, 116-129. https://doi.org/10.1016/j.telpol.2015.07.006

[68] Gill, R. (2011) Why Google Cloud Platform Matters to Finance. Strategic Finance, 92, 43.

[69] Mell, P. and Grance, T. (2011) The NIST Definition of Cloud Computing. NIST Special Publication 800-145. https://doi.org/10.6028/NIST.SP.800-145

[70] El-Gazzar, R.F. (2014) A Literature Review on Cloud Computing Adoption Issues in Enterprises. In: International Working Conference on Transfer and Diffusion of IT, Springer, Berlin, Heidelberg, 214-242. https://doi.org/10.1007/978-3-662-43459-8_14

[71] Luo, X., Li, H., Zhang, J. and Shim, J. (2010) Examining Multi-Dimensional Trust and Multi-Faceted Risk in Initial Acceptance of Emerging Technologies: An Empirical Study of Mobile Banking Services. Decision Support Systems, 49, 222-234. https://doi.org/10.1016/j.dss.2010.02.008 
[72] Vakil, F., Lu, V. and Russakoff, A. (2012) Recent Developments in Google Cloud Platform and High Speed Connections for Business Practices. Review of Business, 33, 111.

[73] Daylami, N., Ryan, T., Olfman, L. and Shayo, C. (2005) Determinants of Application Service Provider (ASP) Adoption as an Innovation. Proceedings of the 38 th Annual Hawaii International Conference on System Sciences, Big Island, HI, 3-6 January 2005, 259b.

[74] Ajzen, I. and Madden, T.J. (1986) Prediction of Goal-Directed Behavior: Attitudes, Intentions, and Perceived Behavioral Control. Journal of Experimental Social Psychology, 22, 453-474. https://doi.org/10.1016/0022-1031(86)90045-4 